\title{
s.t.
}

NASA

AVSCOM

Technical Memorandum 103621

Technical Report 90-C-010

\section{Straddle Design of Spiral Bevel and Hypoid Pinions and Gears}

Faydor L. Litvin, Chihping Kuan, and Jonathan Kieffer University of Illinois at Chicago

Chicago, Illinois

Robert Bossler

Lucas Western Inc.

City of Industry, California

and

Robert F. Handschuh

Propulsion Directorate

- U.S. Army Aviation Systems Command

NASA Lewis Research Center

Cleveland, Ohio

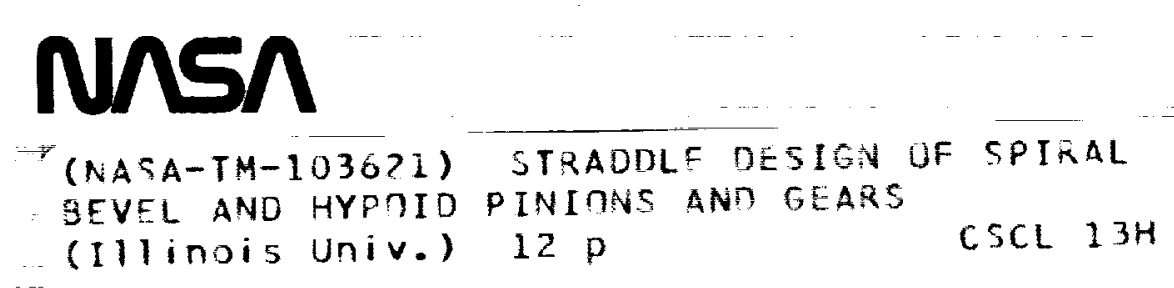


$=\ldots$

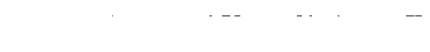


STRADDLE DESIGN OF SPIRAL BEVEL AND HYPOID PINIONS AND GEARS

Faydor L. Litvin, Chihping Kuan, and Jonathan Kieffer

University of Illinois at Chicago

Chicago, Illinois 60680

Robert Bossler

Lucas Western Inc.

City of Industry, California

and

Robert F. Handschuh

Propulsion Directorate

U.S. Army Aviation Systems Command

NASA Lewis Research Center

Cleveland, Ohio 44135-3191

\section{SUMMARY}

The design of spiral bevel and hypoid gears that have a shaft extended from both sides of the cone apex (straddle design) is considered. A main difficulty of such a design is determining the length and diameter of the shaft that might be undercut by the head cutter during gear tooth generation. A method that determines the free space available for the gear shaft is proposed. The approach avoids collision between the shaf $t$ being designed and the head cutter during tooth generation. The approach is illustrated with a numerical example.

\section{INTRODUCTION}

The term "straddle design" means that the gear will be provided with a shaft that extends from both sides of the toothed face of the gear for bearing support. An example of a spiral bevel gear with such a shaf $t$ is shown in $f$ igure 1. The straddle design is preferred for heavily loaded gear trains, since it enables the load to be split between shaf $t$-mounted bearings on both sides of the gear face. The straddle design requires the gear and the shaf to be made as one piece. A design obstacle is the interference (collision) of the shaft with the head cutter during tooth generation.

The valuable experience of Boeing Vertol Company in straddle design has been described by R.J. Drago (ref. 1), who proposed a graphical method for determining the dimensions of an integral shaf $t$ for spiral bevel gears.

In this report a method is proposed for detecting collision of the head cutter with the shaft being designed. The procedure determines the optimal length $u$ of the shaf $t$ and its radius $r$ (fig. 1). The solution is based on determining a space in the plane of parameters $r$ and $u$ that is free from interference with the head cutter. A computer program has been developed that uses the basic machine tool settings for gear generation as input. The computer program results are the diameter $r$ and length $u$ for the lines that limit the space free from undercutting. 


\section{BASIC MACHINE TOOL SETTINGS}

In order to begin to solve this problem, the kinematics of the tooth generation process must be modeled. The basic ideas from which this analytical procedure is developed can be found in reference 2. The process of tooth generation will now be described. The following coordinate systems will be considered:

(1) The coordinate system $S_{0}\left(X_{0}, Y_{0}, Z_{0}\right)$, which is rigidly connected to the cutting machine (figs. 2 and 3 )

(2) The coordinate system $S_{C}$, which is rigidly connected to the cradle that during tooth generation rotates about the $z_{0}$-axis with angular velocity $\omega(\mathrm{c})$

(3) The auxiliary coordinate system $\bar{S}_{p}$, which is rigidly connected to $\mathrm{S}_{0}$ and the gear being generated and rotates about $X_{p}$ with angular velocity $\omega(\mathrm{p})$

(4) The coordinate system $S_{t}$, which is rigidly connected to the head cutter (fig, 4) (note that the head cutter is mounted on the cradle and rotates with it about the $Z_{0}$-axis (fig. 3 ); in addition, the head cutter rotates about the $\mathrm{Z}_{\mathrm{t}}$-axis, but this rotation only provides the required velocity for cutting and is not related to tooth generation)

(5) An additional coordinate system $S_{b}(f i g .2)$, which is rigidly connected to the cradle coordinate system $S_{C}$ and is used to describe the tilt of the head cutter with respect to the cradle

Coordinate systems $S_{t}$ and $S_{b}$ initially coincide with each other. Their orientation with respect to $S_{C}$ is determined with the swivel angle $j$ (fig. 2). The tilt of the head cutter is accomplished by rotating $S_{t}$ (and the head cutter) about the $Y_{b}$-axis by the tilt angle i (fig. 4(b)).

The gear settings (fig. 3 ) are determined with the following parameters: $E_{m}$ (the machine off set); $\gamma_{m}$ (the machine root angle); $\Delta B$ (the sliding base); and $\Delta \mathrm{A}$ (the machine center-to-back distance) (refs. 4 and 5 ).

The head cutter settings (fig. 2) are determined with the following parameters: $S_{R}$ (radial setting); $q$ (cradle angle); $j$ (swivel angle); $i$ ( $t$ ilt angle, not shown in fig. 2). Parameter $q$ is a variable, since the cradle rotates during tooth generation but is constant for Formate ${ }^{1}$ cut gears .

\section{COLLISION OF HEAD CUTTER WITH STRADDLE GEAR SHAFT BEING DESIGNED}

A circle of radius $r_{C}$ on the head cutter (fig. 4) generates a surface in the coordinate system $S_{p}$ while the cradle with the head cutter rotates about the $Z_{0}$-axis ( $f$ ig. 2). This circle may be represented in coordinate system $S_{t}$ in parametric form as follows (fig, 4):

$$
r_{t}=r_{c}\left[\cos \theta_{t} \quad \sin \theta_{t} \quad 0 \quad 1\right]^{T}
$$

The transposed column matrix represents the homogeneous coordinates of a point on circle $r_{C}$.

1Gleason Works trademark. 
The generated surface is represented in coordinate system $S_{p}$ by the matrix equation

$$
r_{p}^{(1)}\left(\theta_{t}, q\right)=\left[M_{p n}\right]\left[M_{n 0}\right]\left[M_{0 c}\right]\left[M_{c b}\right]\left[M_{b t}\right] r_{t}\left(\theta_{t}\right)
$$

Matrix $\left[M_{n 0}\right]$ describes coordinate transformation from $S_{0}$ to an auxiliary coordinate system $S_{n}$ (fig. 3 ) whose axes are parallel to the axes of $S_{0}$.

The superscript in $\mathbf{r}_{p}^{(1)}\left(\theta_{t}, q\right)$ designates surface number 1 (the head cutter surface) that is represented in $S_{p}$. The surface of the shaft in $S_{p}$ will be designated number 2 . Here

$$
\left[M_{c b}\right]=\left[\begin{array}{ccccc}
\cos i & 0 & \sin i & 0 \\
0 & 1 & 0 & 0 \\
-\sin i & 0 & \cos i & 0 \\
0 & 0 & 0 & 1
\end{array}\right]
$$

where $\delta=2 \pi-j$

$$
\begin{aligned}
& {\left[M_{0 c}\right]=\left[\begin{array}{cccc}
\cos q & \sin q & 0 & 0 \\
\sin q & \cos q & 0 & 0 \\
0 & 0 & 1 & 0 \\
0 & 0 & 0 & 1
\end{array}\right]} \\
& {\left[M_{n 0}\right]=\left[\begin{array}{cccc}
1 & 0 & 0 & 0 \\
0 & 1 & 0 & E_{m} \\
0 & 0 & 1 & -\Delta B \\
0 & 0 & 0 & 1
\end{array}\right]} \\
& {\left[M_{p n}\right]=\left[\begin{array}{cccc}
\cos \gamma_{m} & 0 & \sin \gamma_{m} & -\Delta A \\
0 & 1 & 0 & 0 \\
-\sin \gamma_{m} & 0 & \cos \gamma_{m} & 0 \\
0 & 0 & 0 & 1
\end{array}\right]}
\end{aligned}
$$

By using equations (1) to (7), the head cutter surface $\Sigma_{1}$ can be represented as 


$$
\left.\begin{array}{l}
X_{p}^{(1)}=f_{1}\left(\theta_{t}, q\right) \\
Y_{p}^{(1)}=f_{2}\left(\theta_{t}, q\right) \\
Z_{p}^{(1)}=f_{3}\left(\theta_{t}, q\right)
\end{array}\right\}
$$

Now consider a family of coaxial cylinders in coordinate system $S_{p}$ of radius $r_{i}$ (fig. 5) whose equations are represented by

$$
\left.\begin{array}{c}
\mathrm{X}_{\mathrm{p}}^{(2)}=\mathrm{u}_{\mathrm{s}} \\
\mathrm{Y}_{\mathrm{p}}^{(2)}=\mathrm{r}_{\mathrm{i}} \cos \theta_{s} \\
\mathrm{Z}_{\mathrm{p}}^{(2)}=\mathrm{r}_{\mathrm{i}} \sin \theta_{s}
\end{array}\right\}
$$

These coaxial cylinders represent gear shafts of radius $r_{i}$.

Positive and negative signs on $u_{S}$ correspond to the projection of current cylinder point $M$ on the positive or negative axis $X_{p}$. The origin of coordinate system $S_{p}$ coincides with the intersection of the shortest distance with the pinion axis (for a hypoid gear drive) or with the apex of the pitch cone (for a spiral bevel gear drive).

The collision of the head cutter surface $\Sigma_{1}$ with the shaft surface $\Sigma_{2}$ means that the surfaces have a point in common. Thus, the collision can be represented by the vector equation

$$
r_{p}^{(1)}\left(\theta_{t}, q\right)=r_{p}^{(2)}\left(\theta_{s}, u_{s}\right)
$$

which yields

$$
\left.\begin{array}{c}
f_{1}\left(\theta_{t}, q\right)=u_{s} \\
f_{2}\left(\theta_{t}, q\right)=r_{i} \cos \theta_{s} \\
f_{3}\left(\theta_{t}, q\right)=r_{i} \sin \theta_{s}
\end{array}\right\}
$$

The goal is to determine a subspace in the space of parameters $\left(r_{i}, u_{s}\right)$ that is free from collision of $\Sigma_{1}$ and $\Sigma_{2}$. The determination of such a subspace is based on the following computational procedure:

Step 1: Parameter $q$, as mentioned previously is a variable parameter, and its range of variation must be determined. Considering that $\mathrm{q}_{0}$ is the initial value of $q$, the limiting values of $q, q_{1}$ and $q_{2}$, can be determined from the equations

$$
\left.\begin{array}{l}
\mathrm{q}_{1}=\mathrm{q}_{0}-\Delta \mathrm{q} \\
\mathrm{q}_{2}=\mathrm{q}_{0}+\Delta \mathrm{q} \\
4
\end{array}\right\}
$$


where

$$
\Delta \mathrm{q} \geq \frac{\pi}{N_{1}} \sin Y_{p}
$$

$Y_{p}$ is the pitch angle of the gear, and $N_{1}$ is the number of gear teeth.

Step 2: A certain value for $q$ must be chosen in the range $q_{1} \leq q \leq q_{2}$ and then the value of $\theta_{t}$ varied in the range $0 \leq \theta_{t} \leq 2 \pi$. The direct computation allows determination of $r_{i} \cos \theta_{s}$ and $r_{i} \sin \theta_{s}$ from equation (11). Then $r_{i}$ is obtained by taking into account that

$$
\left[\left(r_{i} \cos \theta_{s}\right)^{2}+\left(r_{i} \sin \theta_{s}\right)^{2}\right]^{1 / 2}=r_{i}
$$

Equation (10) is used to determine the values of $u_{S}$ that correspond to $\theta_{S}$.

Step 3: The described computational procedure permits a numerical solu$t$ ion of a family of closed curves $r_{i}\left[u_{s}, q(i)\right](f i g .6)$, where $q(i)$ are the fixed values of $q$. A current point $N$ on each curve of the family of curves in determined with the couple $\left[q^{(i)}, \theta_{t}^{(j)}\right]$, where $q^{(i)}$ is a constant and $\theta_{t}^{(j)}$ is a variable. The subspace in the coordinate system $\left(u_{S}, r_{i}\right)$ that is free from the family of curves determines the values of $r_{i}$ and $u_{s}$ that can be chosen by the designer to avoid collision between the shaft and the head cutter. Recall that the origin of $S_{p}$ coincides with the intersection of the shortest distance with the pinion axis (hypoid) or with the apex of the pitch cone (spiral bevel). A computer program for determining the subspace that is free from collision between the head cutter and the shaf $t$ has been developed.

\section{LIMITING LINES OF SPACE $r_{S}, u_{S}$}

The limiting lines of the space $r_{S}, u_{S}$ are shown in figure 7 for a hypoid pinion. Segments $L_{1}$ and $L_{2}$ of the limiting lines in figure 7 represent the envelopes of the family of closed curves. Segment $\mathrm{L}_{3}$ belongs to the curve with the initial and final value of $q$. Segment $L_{4}$ (fig. 8) represents the limiting line that corresponds to tangency of the bottom of the head cutter (fig. 4) with the set of cylinders of radi $r_{i}$ (fig. 5). Those contact lines are shown in figure 8 .

The limiting lines for the earlier discussion is shown in figure 9. These lines determine the border of the free space where the extended shaft of the pinion can be located. Figure 9 indicates that a shaft of $19 \mathrm{~mm}$ radius can have a length of $40 \mathrm{~mm}$.

The derivation of envelopes $L_{1}$ and $L_{2}$ is based on the following ideas: Consider that the family of planar curves is represented in the shape of parameters $(u, r)$ by the equation

$$
\mathbf{R}=u\left(\theta_{t}, q\right) \mathbf{e}_{u}+r\left(\theta_{t}, q\right) \mathbf{e}_{r}
$$

where $q$ is the parameter of the family. The conditions of envelope existence are represented by the equation (ref. 2) 


$$
N \cdot \frac{\partial R}{\partial q}=f\left(\theta_{t}, q\right)=0
$$

Here

$$
\mathbf{N}=\left[\frac{\partial r}{\partial \theta_{t}}-\frac{\partial u}{\partial \theta_{t}}\right]^{T}
$$

is the normal to a curve of the family. The tangent $T$ to the curve is represented by

$$
\begin{aligned}
& \mathbf{T}=\left[\frac{\partial u}{\partial \theta_{t}} \frac{\partial r}{\partial \theta_{t}}\right]^{T} \\
& \frac{\partial R}{\partial q}=\left[\frac{\partial u}{\partial q} \frac{\partial r}{\partial q}\right]^{T}
\end{aligned}
$$

Equations (15) and (16) considered simultaneously represent the envelope of the family of curves that limits the space $(u, r)$.

The derivation of $\mathrm{L}_{4}$ is based on the idea that the bottom of the head cutter ( $i t$ is a plane) can generate in $(u, r)$ an envelope of a family of planes. Consider that the bot tom of the head cutter is a ring and each circle of the $r$ ing can be represented by its radius $r_{i}$ and a parameter $\theta_{i}$. The envelope generated by the family of $r$ ings is represented in $(u, r)$ by the equations

$$
\left.\begin{array}{c}
u=u\left(r_{i}, \theta_{i}\right) \\
r=r\left(r_{i}, \theta_{i}\right) \\
\sin \theta_{i}=s_{R} \cos i
\end{array}\right\}
$$

The respective values of $\theta_{i}$ can be obtained by varying $r_{i}$. As a reminder, the matrix $\left[\mathrm{M}_{0 \mathrm{t}}\right]$, which describes the coordinate transformation from $S_{t}$ to $S_{0}$, must be used to derive the functions $u\left(r_{i}, \theta_{i}\right)$ and $r\left(r_{i}, \theta_{i}\right)$. Then the points for the limiting line $\mathrm{L}_{4}$ may be selected.

\section{CONCLUDING REMARKS}

A methodology has been proposed that enables spiral bevel or hypoid gear teeth with straddle design to be generated without collision between the head cutter and the shaft. This methodology permits the design of a shaft that extends toward or beyond the gear apex within a given envelope. Equations are used to determine the surface generated by the edge of the head cutter. A zone of safe straddle shaf $t$ design can then be determined.

\section{ACKNOWLEDGMENT}

This research was partially supported by the Gleason Memorial Fund. 


\section{APPENDIX - BASIC PINION MACHINE TOOL SETTINGS}

The data used in the example of this report for determining the free space where the gear shaft can be located are given in the following table:

\begin{tabular}{|l|r|r|}
\hline \multicolumn{1}{|c|}{ Hypoid gear } & \multicolumn{1}{c|}{$\begin{array}{c}\text { Concave } \\
\text { side }\end{array}$} & \multicolumn{1}{c|}{$\begin{array}{c}\text { Convex } \\
\text { side }\end{array}$} \\
\hline Basic tilt angle, deg & 17.260000 & 16.086000 \\
Swivel angle, deg & -31.266000 & -48.216700 \\
Machine root angle, deg & 357.5160 & 357.5830 \\
Cradle angle, deg & 81.21620 & 72.21670 \\
Radial setting, mm & 108.9340 & 111.8520 \\
Sliding base, mm & 19.10001 & 27.64999 \\
Machine center-to-back & -2.650000 & 3.840000 \\
distance, mm & 27.11000 & 31.83000 \\
Blank of fet, mm & 0.2535497 & 0.2371070 \\
Cutting ratio & 112.7750 & 113.4100 \\
Cut ter point radius, mm & & \\
Cutter blade angle, deg & 14.000000 & 31.000000 \\
\hline
\end{tabular}




\section{REFERENCES}

1. Drago, R.J.: On the Design and Manufacture of Integral Spiral Bevel Gears for the CH-47D Helicopter. Presented at the Aerospace Gearing Committee Meeting, AGMA, Lake Tahoe, NV, Mar. 1979.

2. Litvin, F.L.: Theory of Gearing. NASA RP-1212, 1989.

3. Litvin, F.L.; Zhang, Y.; Lundy, M.; and Heine, C.: Determination of Settings of a Tilted Head Cutter for Generation of Hypoid and Spiral Bevel Gears. ASME J. Mech. Transmissions Automation Des., vol. 1, Dec. 1988, pp. 495-500.

4. Litvin, F.L.; and Lee H.-T.: Generation and Tooth Contact Analys is of Spiral Bevel Gears Wi th Predesigned Parabolic Functions of Transmission Errors. NASA CR-4259, 1989.

5. Litvin, F.L., et al.: Hypoid Gear Drive With Face-Milled Teeth: Conditions of Pinion Nonundercutting and Fillet Generation. Proceedings of the 1989 Fall Technical Meeting of the American Gear Manufacturers Association, AGMA, Alexandria, VA, 1989, Paper 7.

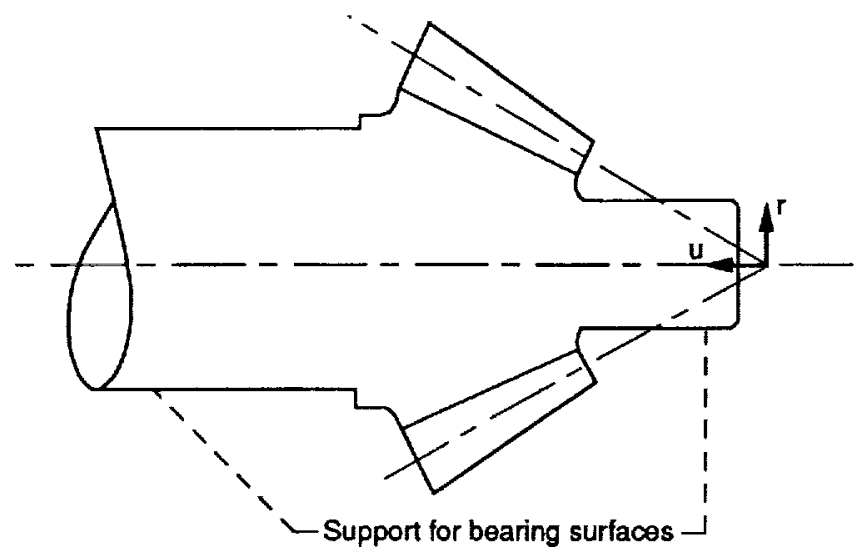

Figure 1. Straddle-design spiral bevel gear showing parameters $r$ and $u$.

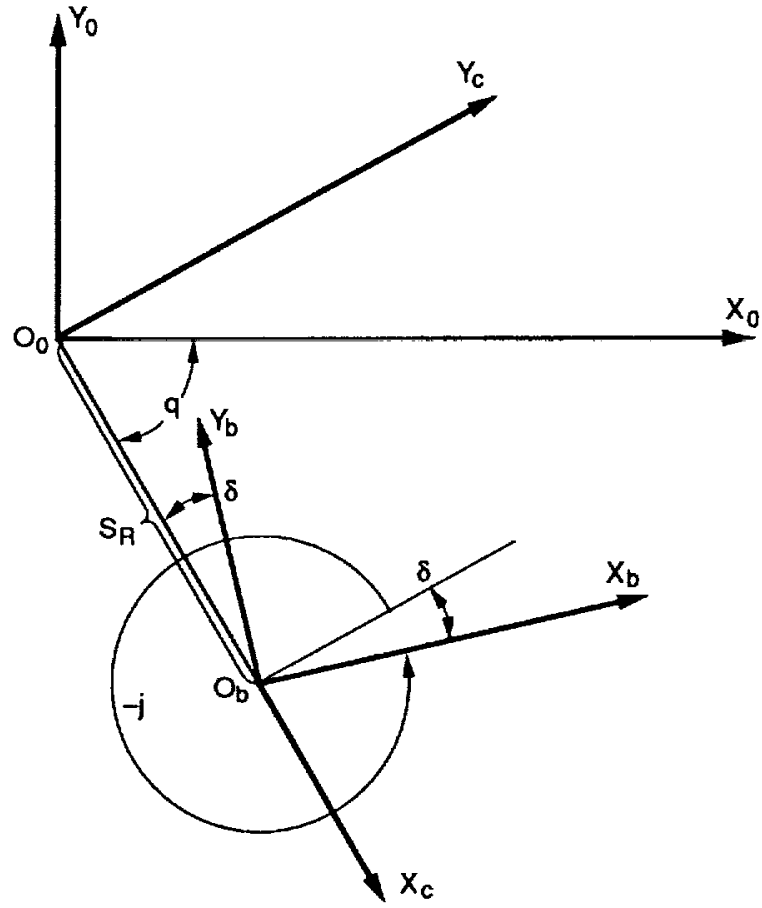

Figure 2.-Cutting machine and cradle coordinate systems. 


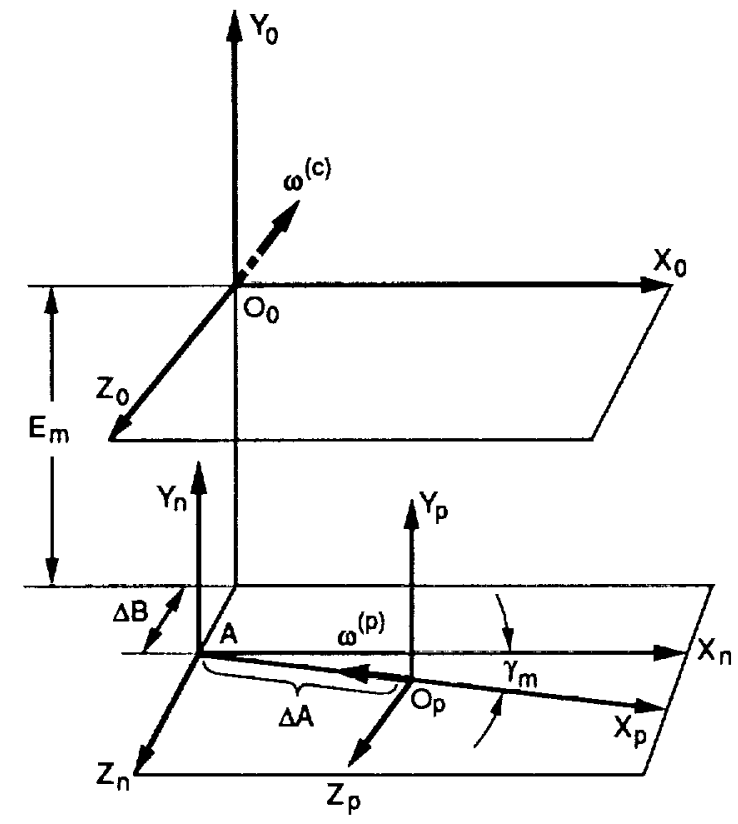

Figure 3.-Angular velocities of cradle and pinion.

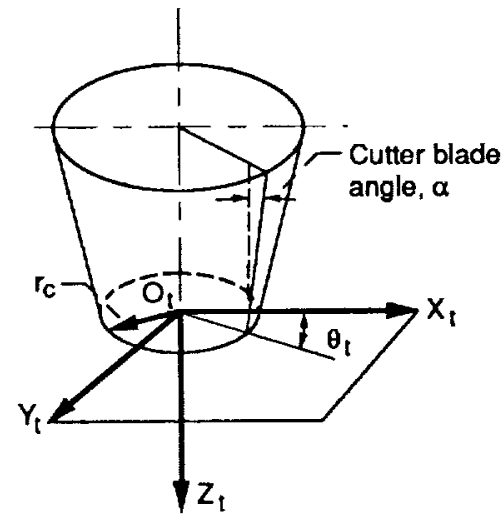

(a) Head cutter surface parameters.

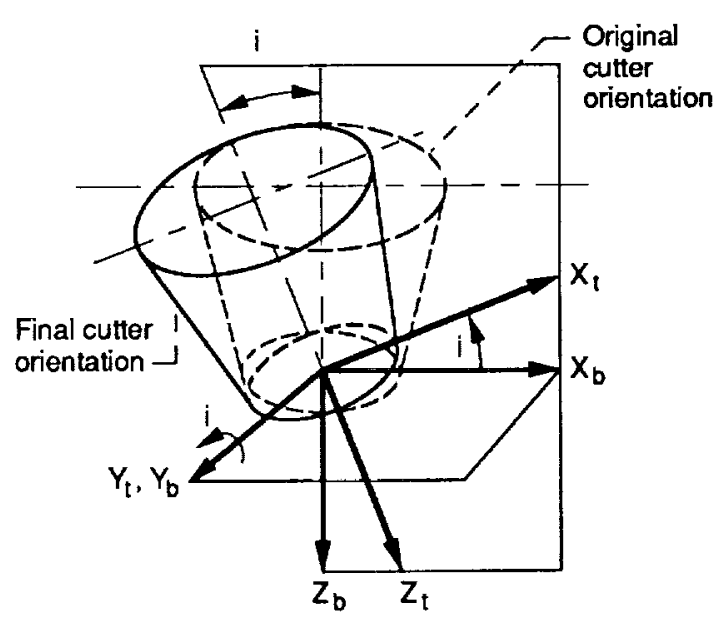

(b) Coordinate systems for head cutter tilt.

Figure 4. Pinion head cutter surface.

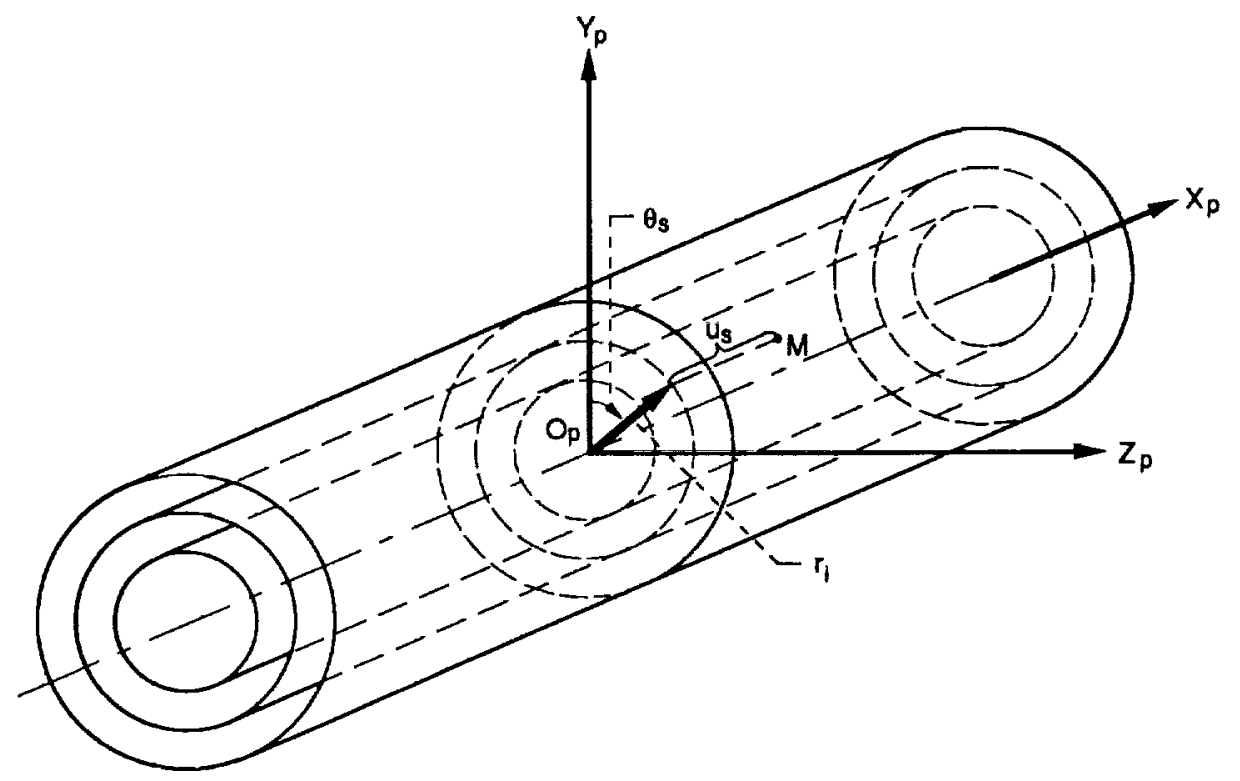

Figure 5.-Family of coaxial cylinders. 


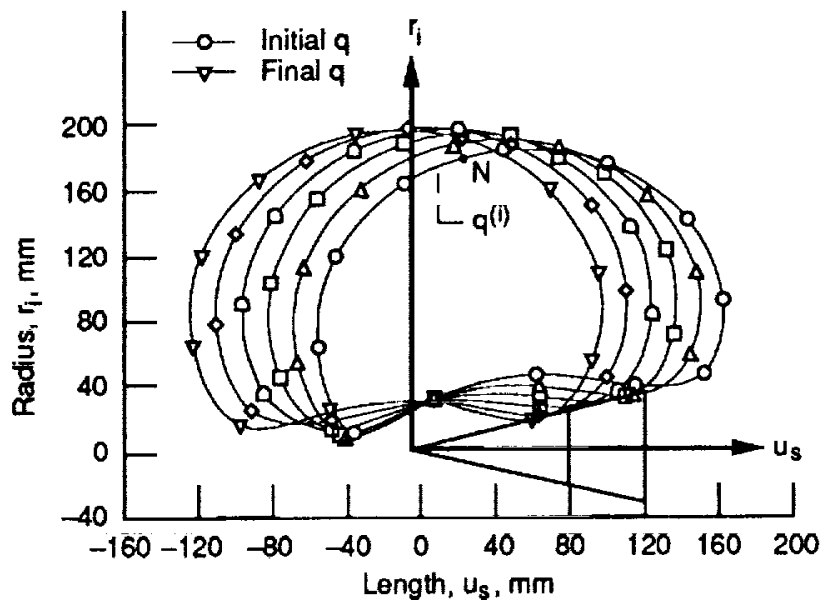

Figure 6.-Family of closed curves.

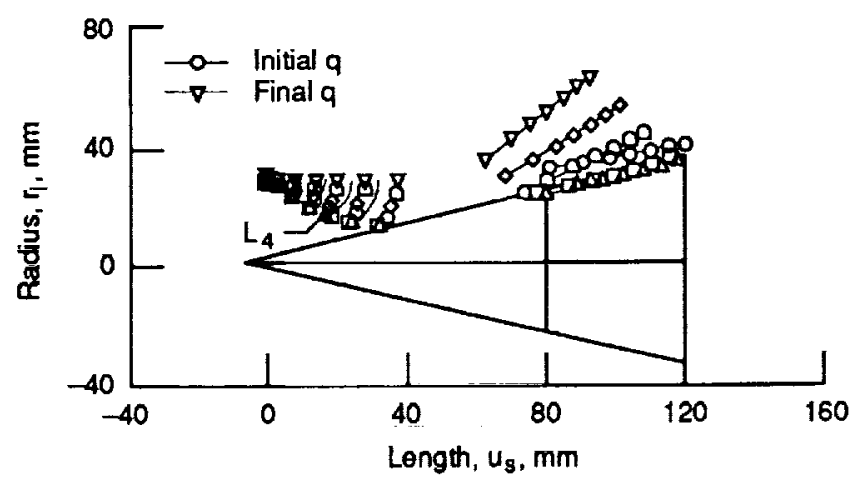

Figure 8.-Limiting lines, $L_{4}$.

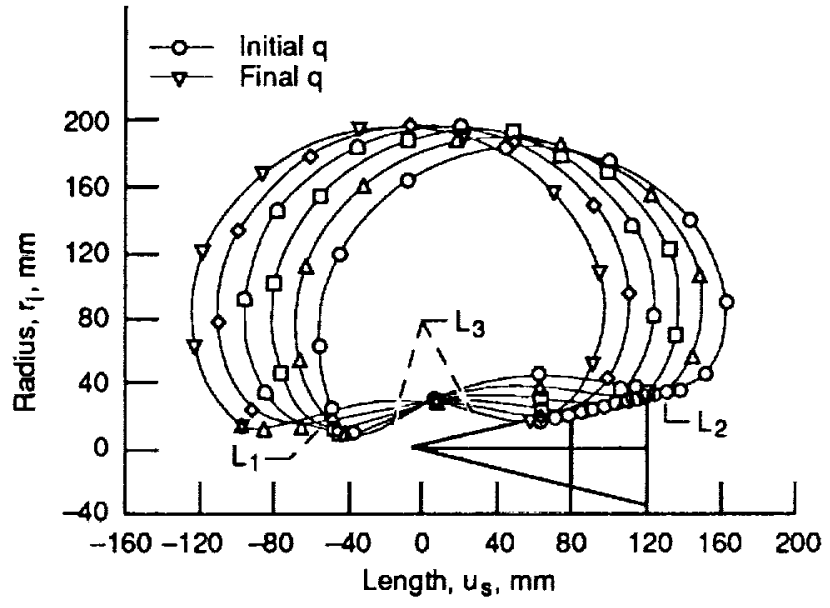

Figure 7.-Limiting lines and envelopes.

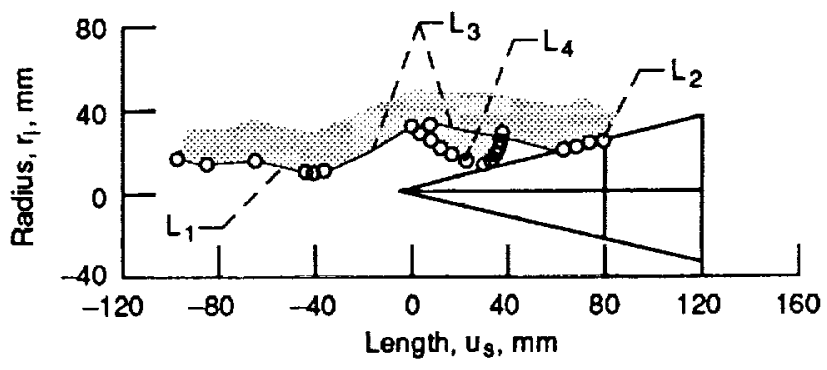

Figure 9. Border of free space. 


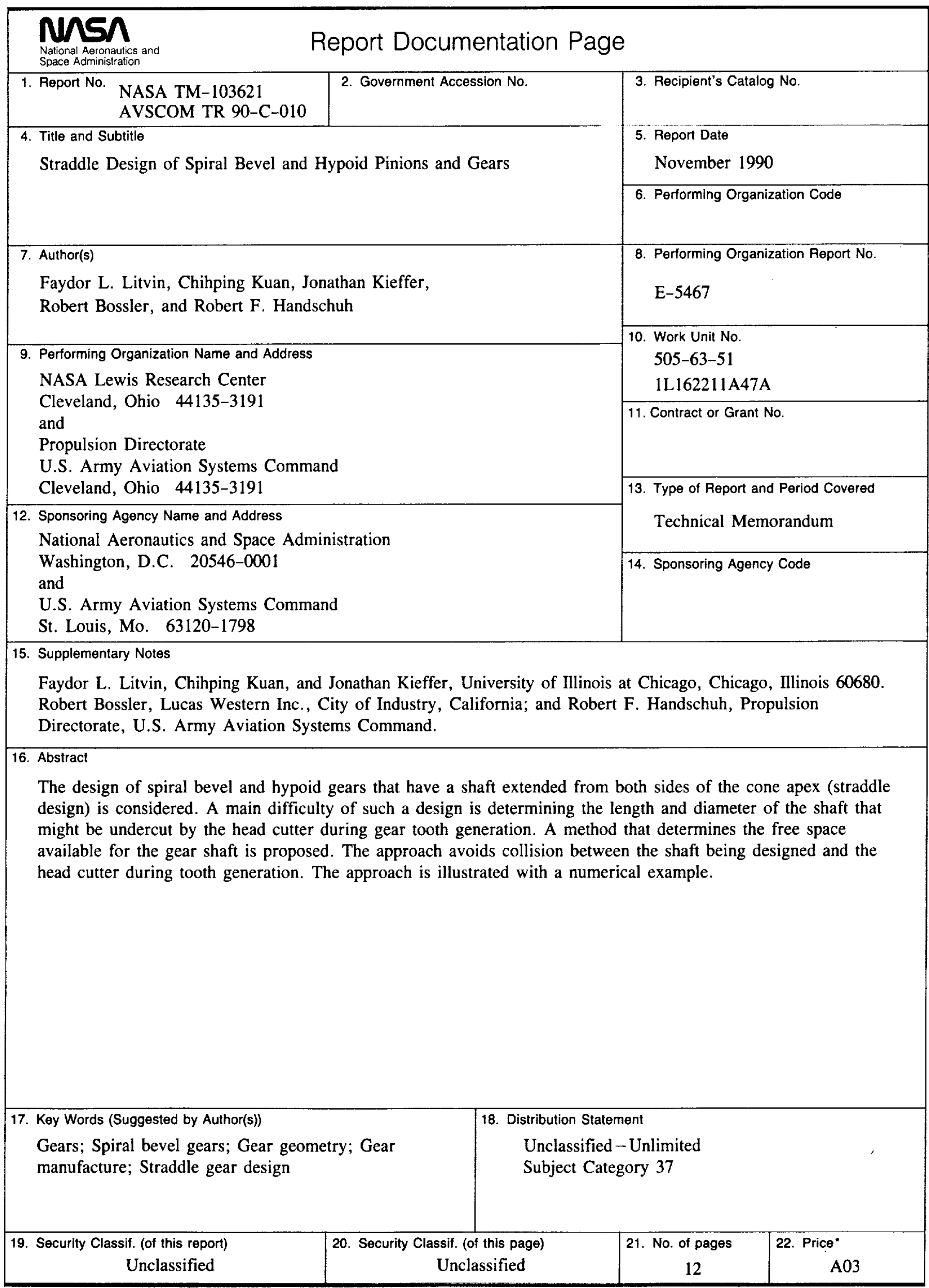


$y$ 